\title{
Effect of the Planting Location (Elevation) on the Composition of Fatty Acids in Olive Oil
}

\author{
Saleh Mohammad Msallam Al-Shdiefat ${ }^{1}$ \\ ${ }^{1}$ Department of Plant Production and Protection, Faculty of Agriculture, Jerash University, Jordan \\ Correspondence: Saleh Mohammad Msallam Al-Shdiefat, Department of Plant Production and Protection, \\ Faculty of Agriculture, Jerash University, Jordan. E-mail: s_shdiefat@yahoo.com
}

Received: September 23, 2018

Accepted: November 6, 2018

Online Published: January 15, 2019

doi:10.5539/jas.v11n2p271

URL: https://doi.org/10.5539/jas.v11n2p271

\begin{abstract}
In Jordan there are different environments and altitudes that have an effect on olive oil properties and fatty acid composition, which therefore affect its quality. Taking into account that there are no previous similar studies in this field, this study investigates the ratios and composition of the main fatty acids in mixed olive oil from different areas in Jordan (above and below the sea level); namely the Jordan Valley, Subaihi, Kufranja and Madaba areas where the elevation ranges between $(-230 \mathrm{~m})$ below sea level and $(+785 \mathrm{~m})$ above sea level. The study measures the impact of the location of olive orchards on the fatty acid composition of olive oil and of its quality. Three olive oil samples were collected from the "Nabali Muhasan" and "Baladi" varieties from each area. They were analyzed in the National Agriculture Research Center (NARC) laboratories using GAS Chromatography. The results showed that the ratios of fatty acids are significantly affected by the degree of above elevation of the olive trees sea level. This confirms the impact of the geographical and climatic environment, which is reflected on the olive oil quality due to differences in the ratios of fatty acids in the four planting areas. This shows that the mean concentration of the fatty acids in the olive oil in these four planting areas is not equal. In general, there is a significant difference in the fatty acid concentrations compared to the standard concentration because of the planting location of olive trees, given that olive oil fatty acids in each location work together in a balanced integrative relationship.
\end{abstract}

Keywords: area elevation, fatty acids, olive oil, olive oil properties

\section{Introduction}

Jordan has a Mediterranean climate with hot, dry summers, and cool, wet winters. However, about $75 \%$ of the country has a desert climate with annual rainfall of less than $200 \mathrm{~mm}$. Jordan can be divided into three main geographic and climatic areas: the Jordan Valley, the Mountain Heights Plateau, and the eastern desert, or Badia region. The Jordan Valley, known in Arabic as the Ghor, is the most fertile area. It extends from the northern border (212 meters below sea level) down to the Dead Sea (at 407 meters below sea level), while the highlands separate the Jordan Valley and its margins from the plains of the eastern desert. This region extends the entire length of the western part of the country. These areas receive Jordan's highest rainfall, and are the most richly vegetated in the country. Elevation in the highlands varies considerably, from 600 meters to about 1,500 meters above sea level, with temperature and rainfall patterns varying accordingly (Jordan, n.d.).

The olive tree in the Hashemite Kingdom of Jordan is spread in intermittent areas where it has been shown (NARC, 2005) that the cultivated areas are equivalent to $52 \%$ of the area planted with fruit trees. In these areas cultivation the trees has many advantages as withstand drought and poor soils. They are the most economical of the fruit trees, and make a significant economic contribution to food security add to their economic as well their significant contribution through their products to food security. Recent research has shown that the production of oil and fruits, as all fatty substances give 9 calories thermal value per 1 gram of olive oil (Khaddam, 2011).

To illustrate the importance of the oil produced by this tree, it has been found that in the last ten years global consumption of olive oil has increased, especially in countries that do not include this oil in their diet (Uccella 2001). The increased demand for its dietary use is not only due to enjoying the qualities required in terms of flavor, taste and color (Alamo et al., 2002), but also to its high nutritional value and numerous health benefits (Fogliano \& Vitaglione, 2002). The quality and value of olive oil depends on different factors including: variety, soil management, climatic conditions, health of the fruit, degree of maturity, method of fruit harvesting and 
transportation and handling (Šarolić et al., 2014; Freihat et al., 2008). In addition to its sensory properties , virgin olive oil contains the required proportions of fatty acids, that make olive oil almost unique as the proportions and the ratios of fatty acids are greater than different types of vegetable oils.

Olive oil is very rich in monounsaturated fatty acid (oleic acid), in addition to other unsaturated fatty acids (Linoleic and Linolenic) (Salvador et al., 2003). Hakan et al. (2017) found that the elevation of the location has an effect on oleic acid, linoleic acid, palmitic acid and stearic acid, which are the main fatty acid components of olive oils. They also found that fatty acid composition had a high correlation with the elevation and the degree of slop. The degree of fusion of olive oil is low compared to other rich vegetable oils and fats as far as saturated fatty acids are concerned. In addition, olive oil is less prone to tingling and oxidation and, compared with vegetable oils, rich in polyunsaturated fatty acids. There is a possibility that oxidation of oils rich in polyunsaturated fatty acids is hundreds of times greater. Oils rich in single acids are unsaturated. Olive trees differ in the content of their components, especially for these fatty acids. Much research in the world for the characterization of olive varieties depends on the ratios of fatty acids (Baeten et al., 1998; Leon et al., 2004), as fatty acid is a genetic characteristic closely related to the class or model, especially palmatic and oleic acid (Dhifi et al., 2002). Some research has been undertaken adopted on this scale with descriptive evidence, such as fruit traits (Bassi et al., 2002; Fourati et al., 2001). Fatty acid ratios in olive oil are affected by several factors identified in some studies: cultivars $(17 \%)$, maturity $(30 \%)$, pressing method $(20 \%)$ and harvesting method $(10 \%)$ and also the period between harvest and fruit pressing $(20 \%)$, (Acar \& Ersoy, 1991). Some such as linoleic acid and oleic acid are also affected, by the conditions in the planted area (Onemli, 2012; Arslan et al., 2013 ) as this study investigates. This research aims to study the composition of olive oil fatty acids, and their proportions in different samples of olive oil collected from sites at different elevations in Jordan.

\section{Materials and Methods}

\subsection{Samples Collection}

Olive oil samples (a mixture of several varieties) were collected from 4 areas in Jordan with different elevations (3 samples for each site, a total of 12 samples), namely: the Jordan Valley ( $-230 \mathrm{~m}$ below sea level), Kufaranja (+680 $\mathrm{m}$ above sea level), Al-Subaihi (+490 $\mathrm{m}$ above sea level) and Madaba (+785 $\mathrm{m}$ above sea level). Olive oil samples were collected in early November during the cropping season 2014/2015, and were then stored in a dark atmosphere at $4{ }^{\circ} \mathrm{C}$. They were then sent to the NARC to conduct the analysis of the fatty acid composition of these samples.

\subsection{Method of Chemical Analysis}

The ratios and composition of fatty acids in olive oil were determined in the olive oil laboratory, where they were analyzed for the collected olive oil samples according to COI/T.20/Doc. No. 24 (2001), based on international commercial specifications of olive oil issued by The International Olive Council (IOC), using a gas chromatography device (GC) Type Shimadzu 2010, which separates fatty acids and determines their types and proportions through methyl derivatives.

Seven (7) $\mathrm{ml}$ of each oil sample was placed in the test tube and mixed with $0.2 \mathrm{ml}$ of HEPTAN. The resulting mixture underwent a strong shaking process, then $0.2 \mathrm{ml}$ of methanolic potassium hydroxide (2N) solution was added. After that it was well fixed and covered with teflon, then well shaken for 30 seconds to form methyl esters. The solution was then left until it stabilized, when the top of the solution became completely clear. Methyl esters were poured here, then separated and evaluated for fatty acids after they had been placed in the refrigerator for no more than 12 hours, and injecting them into a Gas chromatography (GC) device. The results of fatty acids then were expressed as a percentage using the software accompanying the device Chromatography which has been reported in the Appendix A. The data measured was analyzed using the SPSS program and ANOVA table.

\section{Results and Discussion}

\subsection{Fatty Acids Study}

The percentage of Fatty acid composition has an important role both in determining olive oil stability during storage and also its nutritional value (Mailer, 2001). Table 1 shows that the ratios of the major fatty acids in olive oil; oleic, palmetric, linoleic, linolenic and steric acid are within the international and local standards limits for olive oil set by the International Olive Council (IOC,2015), and these values are slightly different depending on the area elevation. Šarolić et al. (2014) report on the quality and biological value of olive oil, consisting of fatty acid composition, the ratio of polyunsaturated to saturated fatty acids, the ratios of omega fatty acids and the amount of total phenols. Oleic fatty acid (single unsaturated) is the main and most important acid in olive oil composition (Eromocele, 2002; Šarolić et al., 2014). It gives the olive oil its characteristics for conservation and 
storage for a long time as compared to other vegetable oils, and increases its nutritional value (Mailer, 2001; Jawad et al., 2002). It helps to form emulsions in the gastrointestinal tract and promotes bile channel secretions, while the main role of olive oil is to regulate the level of cholesterol in blood and reduce heart diseases because it contains a high percentage of single-saturation acids and polyphenols (Wahrburg et al., 2002). The mean values of this fatty acid ranged between $67.72 \%$ and $54.76 \%$ in both Kufranja and the Jordan Valley, respectively, which was similar to those obtained by Gulfraz (2009) in Pakistan. On the other hand, Freihat et al's (2008) results showed that saturated fatty acids (palmitic, stearic, and arachidic) and unsaturated fatty acids (palmitoleic, oleic, linoleic, and linolenic) were influenced by harvesting dates and altitude, whereas palmitoleic acid was not affected at low altitude.

Table 1 . Average rate of fatty acids (\%) in olive oil samples in all studied areas

\begin{tabular}{lllllll}
\hline \multirow{2}{*}{ Fatty Acids } & \multicolumn{4}{c}{ Average \% of the Main Fatty Acids in the studied areas* } & \multirow{2}{*}{ Fatty Acid Standard } \\
\cline { 3 - 6 } & & Madaba $(+785 \mathrm{~m})$ & Subaihi $(+490 \mathrm{~m})$ & Kufranja $(+680 \mathrm{~m})$ & Jor. Valley $(-230 \mathrm{~m})$ & 0.03 \\
C14:0 & Meristic A. & 0.01 & 0.02 & 0.01 & 0.03 & $7.5-20$ \\
C16:0 & Palmatic A. & 16.74 & 13.29 & 14.29 & 18.4 & $0.3-3.5$ \\
C16:1 & Palmatiolic A. & 1.38 & 0.9 & 0.8 & 0.57 & 0.3 \\
C17:0 & Heptadcanwick & 0.07 & 0.18 & 0.18 & 0.16 & 0.3 \\
C17:1 & Heptadsenwick & 0.07 & 0.21 & 0.23 & 3.26 & $55-83$ \\
C18:0 & Stearic A. & 2.39 & 3.65 & 3.33 & 54.76 & $2.5-21$ \\
C18:1 & Oleic A. & 61.87 & 64.23 & 67.72 & 19.40 & 1 \\
C18:2 & Linoleic A. & 15.89 & 15.55 & 11.75 & 1.24 & 0.6 \\
C18:3 & Linolenic A. & 0.81 & 0.9 & 0.78 & 0.57 & 0.4 \\
C20:0 & Aracidic A. & 0.41 & 0.55 & 0.48 & 0.26 & 0.2 \\
C20:1 & Gadiolic A. & 0.21 & 0.34 & 0.29 & 0.05 & 0.2 \\
C22:0 & Bhenic A. & 0.02 & 0.04 & 0.01 & 0.11 & C24:0 \\
\hline
\end{tabular}

Note. * The Average of 3 samples.

Olive oil samples of the Kufranja area show a significant positive advantage for the rest of the studied areas in terms of the high percentage of oleic acid in its olive oil. Results also confirm the differences between the studied samples in terms of their content of these acids as we have observed, which are based on the environment differences among the studied areas where olive trees are planted, which are consistent with Sedgley's (2002) study of the wild model in South Australia.

Percentages of palmitic acid in the studied olive oil samples ranged between $13.29 \%$ and $18.4 \%$ for the Subaihi and Jordan valley areas respectively, and these exceeded the rest. Linoleic and linolenic fatty acids are essential fatty acids that the human body is unable to manufacture and which enter into the cellular membranes and regulate the metabolism of cholesterol in the body. It is desirable that these are in table olives; but they are not suitable for storage, especially linolenic acid, because they are unsaturated fatty acids (Mailer, 2001). However, Freihat et al. (2008) found that oils produced at higher altitude have higher ratios of unsaturated to saturated fatty acid as compared to those at lower altitude. Many unsaturated fatty acids compounds are known to be unstable. When they oxidize they will form compounds known as free radicals that interact with the body wherever they found. However, the presence of antioxidants - phenols and tocopherols - reduces their effect (Kalua, 2005).

Therefore, according to the data in Table 1, the olive oil samples of the Jordan valley are more susceptible to oxidation, due to the increase in the percentage of unsaturated fatty acids (in total) especially in the presence of oxygen, high temperatures and light and therefore they are less susceptible to storage than the other studied samples. At the same time while the values of stearic acid also ranged between $2.39 \%$ and $3.65 \%$, which is relatively high compared to that of some other olive oil producers in the world (Stefanoudaki et al., 1999; Al-Okaby, 2015).

\section{Conclusions}

(1) Different ratios of fatty acids in olive oil based on different elevation sites from sea level lead to a great diversity in the quality of the olive oil.

(2) High elevation olive oil such as that from the Kufranja area, is of good quality and is characterized by long conservation and storage periods as compared with other oils, thus preserving its physical and chemical properties and high nutritional value. 
(3) While olive oil produced below sea level such as in the Jordan Valley area is the most desirable oil on the table but it has the lowest quality of the four sites, and it is the most vulnerable to oxidation and has low storage ability.

(4) Taking the output results concerning quality issues into consideration, it is preferable not to plant more olive trees in the Jordan Valley areas.

(5) The relationship between ratios of the main fatty acids of olive oil is a balanced integrative relationship.

\section{Acknowledgements}

I would like to thank my colleague, Professor Ali Al-Shurafat for his assistance in analyzing the data. My thanks are also extended to the Faculty of Agriculture students; Sharhabeel Al-Balawneh, Qusai Al-Fageer, Yazan Al-Shatarat, Fayez Al-Shobaky and Mohamed Al-Salamat, for their help in collecting olive oil samples from the different elevation areas in Jordan.

\section{Referances}

Acar, H., \& Ersoy, B. (1996). Determination of the Organoleptic Characteristics of the Oils Extracted from Some Important Cultivars in the Aegean Region of Turkey. Olivae, 64, 19-25.

Alemo, R. M., Fregapane, G., Aranda, F., Gomez-Alonso, S., \& Salvador, M. D. (2004). Sterol and alcohol composition of Cornicabra virgen olive oil: The Campesterol content exceeds the upper limit of $4 \%$ established by EU regulations. Food Chemistry, 84, 533-537. https://doi.org/10.1016/S0308-8146(03) 00275-9

Al-Okaby, M. F., Rasmy Nagwa, M., El-Kalyoubi, M. H., \& Girgis, A. Y. (2015). Improving the Extraction Efficiency and Quality of Virgin Olive Oil Using Citric Acid. Middle East Journal of Applied Sciences, 05(1), 148-156.

Arslan, D., Karabekir, Y., \& Schreiner, M. (2013). Variations of phenolic compounds, fatty acids and some qualitative characteristics of Sariulac olive oil as induced by growing area. Food Research International, 54, 1897-1906. https://doi.org/10.1016/j.foodres.2013.06.016

Baeten, V., Hourant, P., Morales, M. I., \& Apericio, R. (1998). Oil and Fat classification by FI-Raman spectocopy. Journal of Agricultural and Food Chemistry, 46(7), 2638-2646. https://doi.org/10.1021/jf97 07851

Bassi, D., Tura, D., Geuna, F., Failla, O., \& Pedo, S. (2002). Characterization of Local Olive (Olea Europaea L.) Accessions by Oil Composition, Morpholoogical and Molecular Markers Methods. ISHS Acta Horticulturae, 586, 57-60. https://doi.org/10.17660/ActaHortic.2002.586.2

Cetinkaya, H., Muhittin, K., Ali, O., Mehmet, A. C., \& Nazım, S. (2017). Influence of Geographical Factors on the Fatty Acid Profile and Oil Yield of Olea europaea L. Scientific Papers. Series A. Agronomy, 11.

Champolivier, L., \& Merrien, A. (1996). Effects of water stress applied at different growth stages to Brassica napus L. var. oleifera on yield, yield components and seed quality. European Journal of Agronomy, 5, 153-304. https://doi.org/10.1016/S1161-0301(96)02004-7

Dhifi, W., Hamrouni, I., Ayachi, S., Chahed, T., Saidani, M., \& Marzouk, B. (2004). Biochemical Characterization of Some Tunisian Olive Oils. Journal of Food Lipids, 11(4), 287-296. https://doi.org/ 10.1111/j.1745-4522.2004.01148.x

Eromocele, C. (2002). Fatty Acid Composition of Seed Oil of Haematataphis Barteri and Ximenia Americana. Tech, 82(3), 4-303.

Fogliano, V., \& Vitaglione, P. (2004). Use of antioxidants to minimize the human health risk associated to mutagenic/carcinogenic heterocyclic amines in food-University of Naples Federico II, Napoli, Campania, Italy. Journal of Chromatography, B 802(1), 189-99. https://doi.org/10.1016/j.jchromb.2003.09.029

Fourati, H., Cossentini, M., Karray, B., \& Khlif, M. (2001). Classification of Olive Trees According to Fruit and Oil Characterizatin. ISHS Acta Horticulturae, 586, 141-145.

Freihat, N. M., Al-Shannag, A. K., \& Assi, N. El (2008). Qualitative Responses of "Nabali" Olive Oil to Harvesting Time And Altitudes at Sub-Humid Mediterranean. International Journal of Food Properties, 11, 561-570. https://doi.org/10.1080/10942910701567356

Gulfraz, M., Kasuar, R., Arshad, G., Mehmood, S., Minhas, N., Asad, M. J., ... Siddique, F. (2009). Isolation and Characterization of Edible Oil from Wild Olive. African Journal of Biotechnology, 8(16), 3734-3738. 
Jawad, M. A., Issa, N. K., \& Ahmed, M. (2002). Some Quality Standards for Syrian Olive Oil Compared to International Quality Standards. Research Days of Syrian-Lebanese Relations (p. 128). Faculty of Agriculture, Tishreen University.

Jordan. (n.d.). Geography and Environment. Retrieved from http://www.kinghussein.gov.jo/geo_env1.html

Kalua, C. M., Allen, M. S., Bedgood Jr., D. R., Bishop, A. G., Prenzler, P. D., \& Robards, K. (2007). Olive oil volatile compounds, flavour development and quality. Food Chemistry, 100, 273-286. https://doi.org/ 10.1016/j.foodchem.2005.09.059

Khaddam, A. (2011). Olive Oil: Its composition, Factors Affecting it and its Health Value. Dar Alaeddin, Damascus-Syria.

Leon, L., Martin, L. M., Uceda, M., \& Jemenez, A. (2004). Variability of Fatty Acid Composition in Olive (Olea europaea L.) Prognies. Spanish Journal of Agricultural Research, 3, 353-359. https://doi.org/10.5424/sjar/ 2004023-89

Mailer, R. (2006). Testing Olive Oil Quality: Chemical and Sensory Methods. NSW Department of Primary Industries.

Onemli, F. (2012). Impact of climate changes and correlations on oil fatty acids in sunflower. Pakistan Journal of Agricultural Science, 49(4), 455-458.

Šarolić, M., Mirko, G., Zvonimir, M., \& Marko, Š. (2014). Virgin olive oil and nutrition. Food in Health and Disease, Scientific-Professional Journal of Nutrition and Dietetics, 3(1), 38-43.

Sedgley, M. (2004). Wild Olive Selection for Quality Oil Product. Rural Industries Research and Development Corporation, 04(104).

Stefanoudaki, E., kotsifaki, F., \& Koutsaftakis, A. (1999). Classification of Virgin Olive Oils of the Two Major Creatan Cultivars Based on their Fatty Acid Compsition. Journal of American Oil Chemists Society, 76(5), 623. https://doi.org/10.1007/s11746-999-0013-7

Wahrburga, U., Kratzb, M., \& Cullenc, P. (2002). Mediterranean diet; olive oil and health. Eur. J. Lipid Sci. Technol., 104(9-10), 698-705. https://doi.org/10.1002/1438-9312(200210)104:9/10\%3C698::AID-EJLT6 98\%3E3.0.CO;2-A

\section{Appendix A}

ANOVA Table of the experiment

\begin{tabular}{|c|c|c|c|c|c|c|c|}
\hline & & & Sum of Squares & $\mathrm{df}$ & Mean Square & $\mathrm{F}$ & Sig. \\
\hline \multirow{4}{*}{ Madaba * Standard } & Between Groups & (Combined) & 3600.839 & 10 & 360.084 & 191760.672 & .000 \\
\hline & Within Groups & & .004 & 2 & .002 & & \\
\hline & Total & & 3600.843 & 12 & & & \\
\hline & Between Groups & (Combined) & 3790.667 & 10 & 379.067 & 223711.484 & .000 \\
\hline \multirow[t]{3}{*}{ Subaihi * Standard } & Within Groups & & .003 & 2 & .002 & & \\
\hline & Total & & 3790.670 & 12 & & & \\
\hline & Between Groups & (Combined) & 4172.807 & 10 & 417.281 & 182973.250 & .000 \\
\hline \multirow[t]{3}{*}{ Kufranj $*$ Standard } & Within Groups & & .005 & 2 & .002 & & \\
\hline & Total & & 4172.811 & 12 & & & \\
\hline & Between Groups & (Combined) & 2959.850 & 10 & 295.985 & 232651.933 & .000 \\
\hline \multirow[t]{2}{*}{ Ghor * Standard } & Within Groups & & .003 & 2 & .001 & & \\
\hline & Total & & 2959.852 & 12 & & & \\
\hline
\end{tabular}

\section{Copyrights}

Copyright for this article is retained by the author(s), with first publication rights granted to the journal.

This is an open-access article distributed under the terms and conditions of the Creative Commons Attribution license (http://creativecommons.org/licenses/by/4.0/). 